\title{
HEALTH AND LIFE STYLE-RELATED DETERMINANTS OF SURVIVAL RATE IN THE MALE RESIDENTS OF THE CITY OF ŁÓDŹ
}

JANUSZ ŚMIGIELSKI ${ }^{1}$, WOJCIECH BIELECKI ${ }^{2}$, and WOJCIECH DRYGAS ${ }^{3}$

\author{
${ }^{1}$ Medical University of Lodz, Łódź, Poland \\ Department of Computer Science and Medical Statistics \\ ${ }^{2}$ Medical University of Lodz, Łódź, Poland \\ Department of Social Pathologies \\ ${ }^{3}$ Medical University of Lodz, Lódź, Poland \\ Department of Preventive Medicine
}

\begin{abstract}
Introduction: The article presents a selected part of an analysis of health- and lifestyle-related determinants of the longevity of male residents of the city of Łódź. The WHO strategy for the European region assumes that the term 'lifestyle' refers to the way of life based on the association between conditions of life understood in a broad sense and individual patterns of behaviour determined by socio-cultural factors and individual features. On this basis, the aim of this study is to identify the multiple statistical relationships on the mortality of men living in Łódź, particularly the influence of the following variables on the probability of survival: age, subjective health assessment, nutritional habits, alcohol consumption and tobacco smoking. Materials and Methods: The study sample (1004 respondents) was selected, and the study was carried out, based on the standards of the CINDI WHO Programme. The investigations included socio-demographic data, health status, lifestyle and anthropometric measurements. Results: From the results of the first- study performed in Poland of the longevity of men with identified risk factors of cardiovascular diseases, it has been found that: 1) Tobacco smoking has a negative influence on male longevity; 2) Alcohol consumed in moderate amounts favours male longevity; 3) The level of physical activity observed among the studied men was too low to affect longevity; 4) A diet rich in fish and consumption of yellow cheese are positive predictors of longevity, while additional use of table salt at meals and consumption of sweets (cakes) are negative ones. Conclusions: Risky lifestyles and a reluctance to abandon them are responsible for a shorter lifespan among men in Poland. Reducing this difference between women and men is a real challenge for public health professionals and preventive medicine specialists.
\end{abstract}

Key words:

Longevity, Physical activity, Nutritional habits, Alcohol consumption, Tobacco smoking, Pro-health behaviours

\section{INTRODUCTION}

Chronic Non-communicable diseases (CNCDs) are nowadays a leading cause of death worldwide. The global WHO report on NCDs [1] has revealed that over $2 / 3$ of total deaths result from cardiovascular diseases (48\%), cancers
(21\%), chronic respiratory diseases $(12 \%)$ and diabetes mellitus (3\%) [2]. Almost one fourth of them is referred to as premature deaths, i.e. those which afflict people younger than 60 . This situation is a sufficient reason for permanent monitoring of the pattern of CNCDs, as well

Received: September 25, 2012. Accepted: March 6, 2013.

Corresponding author: J. Śmigielski, Department of Computer Science and Medical Statistics, Medical University of Lodz, Plac Hallera 1, 90-647 Łódź, Poland (e-mail: janusz.smigielski@umed.lodz.pl). 
as for enlarging and disseminating the knowledge on their risk factors, among which a special place is attributed to the diseases related to lifestyle [3].

The behavioural, i.e. reversible, risk factors (RF) such as low level of physical activity, excessive alcohol consumption, tobacco smoking and improper diet, on the one hand, and the psychological and metabolic RFs (BMI) as well as sociodemographic determinants on the other hand, such as sex, the level of education, income per capita in a family, and the level of available health care system services, are taken into consideration [1]. Generally speaking, direct indicators evaluating the health status of a population are not available. The use of individual opinions may lead to research bias. According to a Social Research Agency (PBS) report, $68 \%$ of the Polish population believe they lead a healthy life style and $74 \%$ are convinced that their diets are healthy [4].

A growing number of sources indicate that modification of life style may not only affect life quality but also effectively decrease the mortality rate and need for health care services $[5,6]$.

These premises constitute the basis for this study on the multiple relationships between the mortality of men living in Łódź (a large industrial city in the centre of Poland) and such characteristics as the level of physical activity, dietary habits, alcohol consumption and tobacco smoking. According to recently published analyses, the general mortality for Łódź inhabitants in 2007-2012 was comparable to that of the general population of Poland, with a standardized mortality ratio of 1.097; however, it was significantly higher than that recorded for the urban populations of Warszawa or Gdańsk, with respective standardized mortality ratios of 0.831 and 0.867 [7].

\section{MATERIALS AND METHODS}

The study sample (1004 respondents) was examined in 2001 as part of the Countrywide Integrated Noncommunicable
Diseases Intervention (CINDI) Programme (2001) for the World Health Organization (WHO); the study being performed according to the methodological standards of the Programme. The study methods, the method of selecting the representative sample of the subjects to be examined, the system of sending invitations to visit the Medical University and the rules of carrying out socio-medical, analytical and medical studies were developed by a team of experts from the Medical University of Lodz [8]. The median age of the subjects was 43 years (mean age: 41 , standard deviation: 13.8 years).

\section{Data on healthy behaviours}

Basic characteristics (variables) were related to selected health behaviours and socio-demographic characteristics. The study comprised general data (age, place of residence); elements of lifestyle, such as alcohol consumption (strong alcohol, wine, beer); smoking history; dietary habits: additional use of table salt at meals, intake of beef, fish, vegetables and fruit, cakes and soft drinks. Body Mass Index (BMI) values higher than 30 were recognized as indicating obesity.

\section{Analysis of mortality data}

In the studied period, i.e. 1.01.2004 until 31.12.2009, 56 deaths were recorded, including 16 from cardiovascular diseases, 13 from cancers, 8 from external causes, 4 from digestive system diseases, 2 from respiratory diseases and 13 of unknown origin. Due to the small number of deaths and the relatively short period of the study, the overall mortality rate was analysed. Data on the specific causes of deaths were obtained from the Central Statistical Office.

\section{Statistical analysis}

To compare survival curves, nonparametric tests of significance suitable for censored observations were used, i.e. Gehan's generalised Wilcoxon test, Cox-Mantel test, log-rank test; Peto and Peto's generalised Wilcoxon test and Cox's F test. 
In order to investigate the combined effect of the analyzed variables and determine the size of the impact of these variables, as a hazard ratio, it was decided to design statistical models containing several variables of the eating habits together . For the multivariate analysis, the Cox proportional hazards model was used.

In the Cox proportional hazards model, it is assumed that in addition to the hazard function $\lambda_{\mathrm{i}}(\mathrm{x})$, the observation is still subject to a set of $\mathrm{i}$-dimensional vectors of explanatory variables $y=\left(\mathrm{y}_{1}, \mathrm{y}_{2}, \ldots, \mathrm{y}_{\mathrm{t}}\right)^{\mathrm{T}}$. In practice, such a vector can be defined, for example, as patient characteristics, which are mostly demographic variables, medical or environmental determinants.

Furthermore, let $\lambda_{\mathrm{i}}(\mathrm{x})$ denote the hazard function of the random variable $\mathrm{T}_{i}$. In the Cox model:

$$
\lambda_{\mathrm{i}}(\mathrm{x})=\lambda(\mathrm{x}) \exp \left(\beta \times \mathrm{y}_{\mathrm{i}}\right)
$$

where:

$\lambda_{\mathrm{i}}(\mathrm{x})$ - a hazard function identical for all random variables.

$\mathrm{T}_{\mathrm{i}}$ and the function $\lambda(\mathrm{x})$ is unspecified. Models specified by this equation are called semi-parametric models.

As a strategy of composition, a multiple regression model was used with a backward stepwise procedure. At the start point, a full model containing all influential variables was constructed, and one variable with the greatest $\mathrm{p}$-value was eliminated from the model at each step. The procedure stops when none of the variables fulfil the cut-off criteria $(\mathrm{p}>0.1)$.

The difference between the two survival functions is considered statistically significant if $\mathrm{p}<0.05$. In this work, STATISTICA 8.0 was used for all statistical calculations .

\section{RESULTS}

\section{Age}

The analysis of the survival function for the study population showed a systematic, statistically significant decrease in the survival curve during the examined period together with the age of the subjects. The hazard ratio for the variable "age" was 1.1, which means that each year increases the probability of death by 0.1 in the examined residents of Łódź (Figure 1).

\section{Education}

Men with higher education had the highest probability of survival, while the lowest probability was noted among those with only primary education. However, the observed differences were not statistically significant (Table 1).

\section{Physical activity}

The variable "physical activity" did not appear to be statistically significant as regards the analysis of probability of survival (Table 1).

\section{Tobacco smoking}

The statistical analysis showed a negative impact of smoking on general health status and average lifespan, both in present and former smokers (Table 1 and Figure 2).

\section{Alcohol}

The results of the statistical analysis for variables "drinking wine" (Figure 3) and "drinking beer" (Figure 4) in the group of men indicated a positive effect of moderate consumption of these alcoholic drinks on life duration. No differences in lifespan distribution were observed between the men who were consumers of at least one type of drink and those who

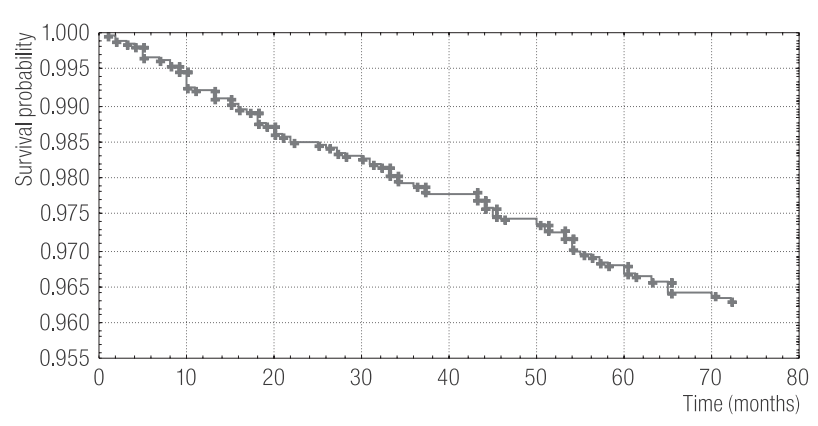

Fig. 1. Survival probability in a representative group of male residents of Łódź according to the time of observation 
Table 1. The Cox proportional hazards regression model - the results of univariate analyses in the group of male residents of Łódź

The Cox proportional hazards regression model

Dependent variable: observation time (in months)

\begin{tabular}{|c|c|c|c|c|c|}
\hline \multirow[b]{2}{*}{ Explanatory variables } & \multicolumn{5}{|c|}{ numerical characteristics of the model } \\
\hline & $\begin{array}{c}\text { beta parameter } \\
\text { estimates } \\
\text { (value) }\end{array}$ & $\begin{array}{c}\text { asymptotic } \\
\text { standard error } \\
\text { of parameters }\end{array}$ & hazard ratio & $\begin{array}{l}\text { wald statistic } \\
\text { value }\end{array}$ & $\begin{array}{c}\text { probability level } \\
\text { of the wald } \\
\text { statistic } \\
\end{array}$ \\
\hline Age (continuous variable) & 0.075 & 0.013 & 1.08 & 32.73 & 0.000 \\
\hline $\begin{array}{l}\text { Education (primary education vs. more than } \\
\text { primary) }\end{array}$ & 0.078 & 0.108 & 0.92 & 0.53 & 0.466 \\
\hline $\mathrm{BMI}(\leq 30$ vs. $>30)$ & 0.539 & 0.086 & 1.71 & 3.05 & 0.081 \\
\hline $\begin{array}{l}\text { Physical activity (small or not at all vs. moderates } \\
\text { vs. high) }\end{array}$ & 0.064 & 0.291 & 1.06 & 0.05 & 0.824 \\
\hline Tobacco smoking (smokers vs. nonsmokers) & 0.652 & 0.302 & 1.92 & 4.67 & 0.031 \\
\hline Tobacco smoking (ex-smokers vs. nonsmokers) & 0.640 & 0.302 & 1.90 & 4.49 & 0.034 \\
\hline Spirits (not at all vs. moderate use) & -0.458 & 0.326 & 1.98 & 0.63 & 0.159 \\
\hline Beer drinking (not at all vs. moderate use) & -0.688 & 0.290 & 0.50 & 5.60 & 0.018 \\
\hline Wine drinking (not at all vs. moderate use) & -0.902 & 0.296 & 0.41 & 9.29 & 0.002 \\
\hline Salt consumption (yes vs. no) & 0.537 & 0.280 & 1.71 & 3.68 & 0.049 \\
\hline $\begin{array}{l}\text { Pork or beef }(\leq 2 \text { times/week vs. } 3-5 \text { times/week } \\
\text { vs. } 6-7 \text { times/week) }\end{array}$ & 0.426 & 0.212 & 1.53 & 4.01 & 0.045 \\
\hline Fish (not at all vs. $1-2$ vs. $3-7$ days/week) & -0.540 & 0.250 & 0.55 & 4.67 & 0.040 \\
\hline Yellow cheese (not at all vs. $1-2$ vs. $3-7$ days/week) & -0.648 & 0.291 & 0.52 & 4.98 & 0.026 \\
\hline Cakes (not at all vs. $1-2$ days vs. $5-7$ days/week) & -0.254 & 0.170 & 0.78 & 2.23 & 0.068 \\
\hline $\begin{array}{l}\text { Vegetables consumption ( } \leq 2 \text { days vs. } 3-5 \text { vs. } 6-7 \\
\text { days/week) }\end{array}$ & 0.121 & 0.274 & 1.29 & 0.20 & 0.659 \\
\hline Fruits in diet (yes vs. no) & 0.649 & 0.593 & 1.91 & 1.20 & 0.274 \\
\hline Soft drinks (yes vs. no) & -0.113 & 0.291 & 0.89 & 0.15 & 0.698 \\
\hline Type of fat used at home (vegetable oil vs. others) & -0.393 & 0.404 & 0.68 & 0.95 & 0.331 \\
\hline Use butter or margarine (yes vs. no) & 0.108 & 0.223 & 1.11 & 0.24 & 0.628 \\
\hline
\end{tabular}

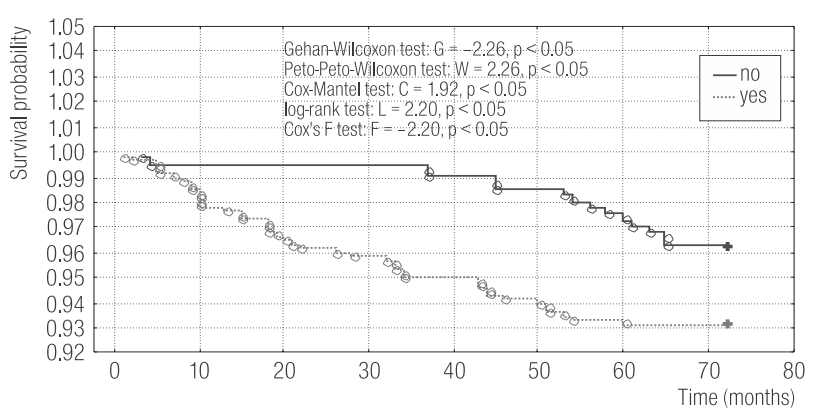

Fig. 2. Survival probability in the representative group of male of residents according to the variable "history of tobacco smoking" were non-drinkers. There was no correlation between the consumption of strong alcohol and lifespan (Table 1).

\section{Diet}

The results of the statistical analysis revealed that "additional use of table salt at meals" was a statistically significant determinant of life duration (Figure 5). Regarding other diet variables, only frequent consumption of pork or beef was negatively related to survival probability. The effect of 


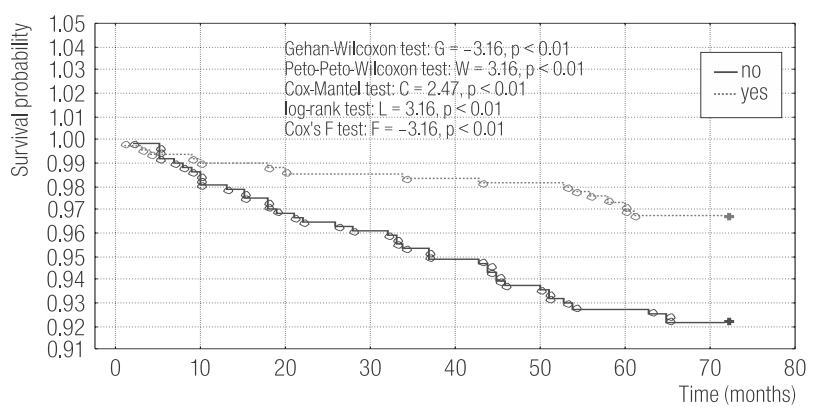

Fig. 3. Survival probability in the representative group of male residents of Łódź according to the variable "drinking wine"

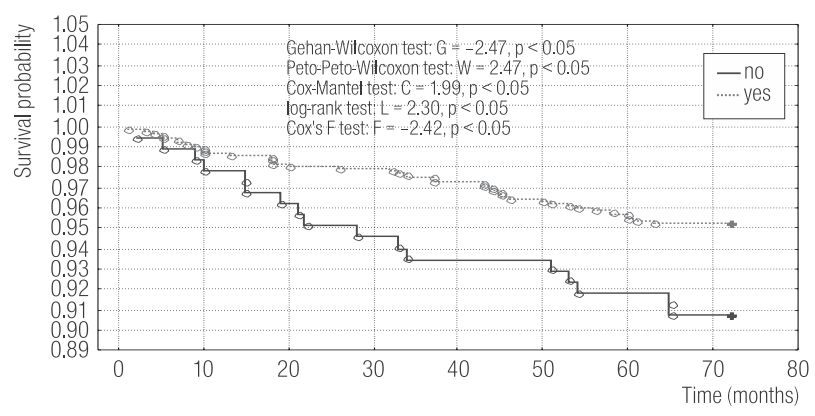

Fig. 4. Survival probability in the representative group of male residents of Łódź according to the variable "drinking beer"

'cakes' was negative as well, albeit on a borderline level. On the other hand, consumption of fish and yellow cheese had a positive influence (Table 1). Frequent consumption of vegetables, fruits and soft drinks did not show any statistical significance as a determinant of life duration ( $p>0.05)$.

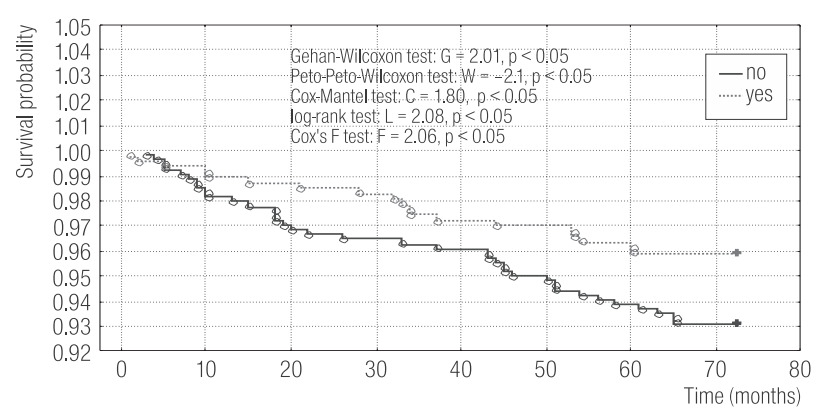

Fig. 5. Survival probability in the representative group of male residents of Łódź according to the variable "additional use of table salt at meals"
Similarly, consumption of vegetable oil in general and butter or margarine on bread did not show any statistical significance as a determinant of life duration $(p>0.05)$. The highest values of predicted life expectancy in this regard were noted in the respondents who did not use any fats on bread, followed by those who buttered bread; the worst results were achieved by the subjects who used margarine.

\section{Multivariate analysis - diet}

In order to investigate the combined effect of the analysed diet variables and to determine their magnitude, in the form of a hazard ratio, statistical models containing a combined analysis of four variables concerning nutritional habits were constructed. Consumption of "beef or pork meat", and "cakes" was found to negatively correlate with the probability of survival, while "fish" and "yellow cheese" had a significant positive influence (Table 2). However when age was added as a confounding factor, only "yellow cheese" remained a positive and "beef or pork meat" as a negative survival risk factor (Table 3 ).

\section{DISCUSSION}

\section{Age}

Age is a well-known predictor of mortality. In the performed analysis, the hazard ratio for the variable for "age" was 1.1 , which signifies that probability of death in the population studied increases by $10 \%$ each year. This value is close to the one derived from Life Tables compiled by the Central Statistical Office, according to which the probability of death of a Polish citizen increases by $9 \%$ each subsequent year: the value calculated for men and women aged 30-80.

\section{Education}

In our analyses, men with higher education had higher probabilities of survival compared with those with low education, although this difference was not significant. 
Table 2. The Cox proportional hazards regression model for the "food products" variable in the group of male residents of Łódź the results of multivariate analyses (age not included)

\begin{tabular}{|c|c|c|c|c|c|}
\hline \multirow{2}{*}{$\begin{array}{l}\text { Explanatory } \\
\text { variables }\end{array}$} & \multicolumn{5}{|c|}{$\begin{array}{l}\text { Dependent variable: observation time (in months) } \\
\text { Numerical characteristics of the model }\end{array}$} \\
\hline & $\begin{array}{l}\text { beta parameter } \\
\text { estimates (value) }\end{array}$ & $\begin{array}{l}\text { asymptotic standard } \\
\text { error of parameters }\end{array}$ & hazard ratio & wald statistic value & $\begin{array}{c}\text { probability level of } \\
\text { the wald statistic }\end{array}$ \\
\hline Pork beef & 0.92 & 0.43 & 2.52 & 4.52 & $\mathrm{p}<0.05$ \\
\hline Fish & -0.56 & 0.27 & 0.57 & 4.30 & $\mathrm{p}<0.05$ \\
\hline Yellow cheese & -0.66 & 0.31 & 0.52 & 4.59 & $\mathrm{p}<0.05$ \\
\hline Cakes & 0.65 & 0.32 & 1.93 & 4.19 & $\mathrm{p}<0.05$ \\
\hline
\end{tabular}

Evaluation of matching the model to empirical data: chi-square test $=19.06, \mathrm{p}<0.01$.

Table 3. The Cox proportional hazards regression model for the "food products" variable in the group of male residents of Łódź - the results of multivariate analyses (age included)

\begin{tabular}{lccccc}
\hline \multirow{2}{*}{$\begin{array}{c}\text { Explanatory } \\
\text { variables }\end{array}$} & \multicolumn{5}{c}{$\begin{array}{c}\text { Dependent variable: observation time (in months) } \\
\text { Numerical characteristics of the model }\end{array}$} \\
\cline { 2 - 6 } & $\begin{array}{c}\text { beta parameter } \\
\text { estimates (value) }\end{array}$ & $\begin{array}{c}\text { asymptotic standard } \\
\text { error of parameters }\end{array}$ & hazard ratio & wald statistic value & $\begin{array}{c}\text { probability level } \\
\text { of the wald statistic }\end{array}$ \\
\hline Age & 0.07 & 0.01 & 1.07 & 49.00 & $\mathrm{p}=0.000$ \\
Pork beef & 1.02 & 0.51 & 2.77 & 4.00 & $\mathrm{p}<0.050$ \\
Fish & -0.42 & 0.25 & 0.66 & 2.88 & $\mathrm{p}=0.094$ \\
Yellow cheese & -0.60 & 0.29 & 0.55 & 4.28 & $\mathrm{p}<0.050$ \\
Cakes & -0.65 & 0.32 & 1.93 & 4.19 & $\mathrm{p}=0.077$ \\
\hline
\end{tabular}

Evaluation of matching the model to empirical data: chi-square test $=48.12, \mathrm{p}<0.001$.

Higher mortality rates in less-educated individuals can be observed in recent WHO analyses of social inequalities in health in Poland. In 2002, the average life expectancy of persons aged 25 years with post-secondary or tertiarylevel education, compared to people with no secondary education, was 13 years longer in men and 9 years longer in women [9].

\section{Diet}

A comparison of the "food products" variables against the death distribution of the study group of the male residents of Lódź indicated two variables with a negative influence on predicted life expectancy, "beef and pork consumption" and "cake consumption", and two positive variables, "fish consumption" and "yellow cheese consumption". When age was included in the models only "cakes" and "yellow cheese consumption" remained significant factors

There is little information in the available literature on the positive effect of excessive consumption of yellow cheese and cakes, as well as on the harmful impact of eating beef. On the other hand, there are many reports on the beneficial effect of a diet rich in fish and seafood. However, they are ambiguous. Attention has been drawn to the potential benefits resulting from a diet rich in fish and seafood, which has been observed among the Inuit population in Greenland, 
where a low prevalence of chronic diseases occurs, mostly due to a fish-based diet [10]. A number of studies suggest that the opposite relationship is true between everyday consumption of fish and the prevalence of ischemic disease [11] and stroke [12]. These premises are reflected in dietary recommendations to consume at least two portions of fish per week, one of which should be fatty fish [13].

"Use of table salt at meals" was found to be significant in the univariate analysis. These findings are in agreement with the recommendations of the WHO and other scientific associations, according to which consumption of salt should be limited to 5-6 g daily, as excessive use of salt increases the risk of hypertension and some neoplasms. Adding more salt to meals should be avoided; consumption of tinned and processed food containing high amounts of salt should be also limited in favour of meals prepared from fresh food [14-16].

Although not confirmed in our analyses as predictor of survival, vegetables and fruit constitute an important source of vitamins, mineral components, fibre and flavonoids. Sufficient amounts of these components can be provided by consuming at least $400 \mathrm{~g}$ of vegetables and fruit per day. Any additional portion of fruit and vegetables in the diet decreases the risk of cardiovascular events by $4 \%$, and the risk of stroke by $5 \%$ [17].

This indicated lack of significance for "buttering bread", "fruit-" and "vegetable consumption" is difficult to accept. Especially when considering that these results appear to contradict the literature on the relationships between using proper types of fats to prepare meals and the duration of life. Therefore, the relationships obtained in the present study should be confirmed on a larger group of subjects and by means of a more precise questionnaire concerning this issue.

\section{Alcohol}

Consumption of alcohol in moderate amounts (both wine and beer) was a factor that positively affected duration of life. However, no correlation was observed between drinking strong alcohol and duration of life. Such results might be caused by the definition of the variable being too general, ie. "drink" or "do not drink"; whereas in the case of strong alcohol, a parabolic correlation is usually found between consumption magnitude and life duration. The lowest values of average predicted life expectancy are attributed to individuals declaring a complete abstinence or a high consumption of alcohol, whereas the highest values are associated with subjects who declare moderate consumption.

The effect of ethanol on overall mortality rates observed in many epidemiological studies performed in different countries is usually presented as a J-or even U-shaped curve in a graph [18], implying that mortality due to cardiovascular diseases is higher among teetotallers and heavy drinkers than in people who consume moderate amounts of alcohol. However, apart from the quantity, the frequency of consumption and type of alcohol consumed are also significant in achieving the potential benefits resulting from the protective action of alcohol against atherosclerosis and balancing a negative impact on health [19]. Thus, it is assumed that the limit of reasonable drinking is no more than four standard portions, or rather $10 \mathrm{~g}$ of pure ethanol: a glass $(200 \mathrm{ml})$ of beer, a glass of wine $(100 \mathrm{ml})$ or a small glass of vodka $(25 \mathrm{ml})$ not more than five times per week. However, even the amounts given above do not eliminate the risk of addiction and health damage, the symptoms of which may occur in some cases within 3-4 years from the time of the first incidence of alcohol consumption [20]. Another issue in discussing the effect of alcohol on general health status is the consumption of wine, especially red wine, which has recently become the subject of interest of specialists from different medical fields. The majority of scientific studies focus on the phenomenon of the so called "French paradox", i.e. significantly lower morbidity and mortality rates due to ischemic diseases in France and other Mediterranean countries, despite a relatively high consumption of animal fats and 
saturated fatty acids. Regular consumption of moderate amounts of red wine (200-400 ml/day) seems to play a protective function against ischemic disease and other cardiovascular diseases, likely including some types of neoplasms, diabetes or osteoporosis. Once again, however, bearing in mind the potential risks associated with alcohol consumption, especially the risk of alcoholism, recommendations concerning the consumption of red wine should be formulated with great caution [21,22]. Excessive alcohol consumption in any form is the basis of addiction, which may be the cause of numerous serious diseases, disability and premature death, due to accidents, including traffic accidents, or suicides. In the 1990s, the number of people addicted to alcohol was estimated at 62 million, of which 7 million were inhabitants of Middle and Eastern Europe [20].

\section{Tobacco smoking}

As expected, smoking was a significant predictive factor for further duration of life in the population studied. The argumentation that smoking is negatively correlated with life duration is today indisputable; nevertheless, it is worth reviewing some epidemiological reports. It has been estimated that one out of three smokers will die prematurely due to complications induced by smoking. Tobacco smoking is the most frequent cause of various malignant diseases, predominantly lung cancer, chronic obturative lung disease and cardiovascular diseases including ischemic heart disease and peripheral vascular diseases [23,24]. Calculations by Paffenberger et al. reveal that mortality rates due to cardiovascular diseases are nearly $25 \%$ lower among non-smokers than among smokers [25]. Moreover, it has been proven that smokers die on average 8 years earlier than non-smokers, whereas heavy smokers (more than 20 cigarettes per day), 10 years earlier. A reduction in smoking, as well as changes in physical activity and food habits, exert an influence on individual life duration [21].

\section{Physical activity}

The results of the statistical analysis do not identify any statistically significant differences regarding "physical activity" variants with respect to the distribution of life duration. This result is surprising when considering the fact that there are currently no doubts that regular physical exercise of adequate intensity, frequency and duration is a significant factor preventing the development of obesity. The results of longitudinal prospective trials indicate that occurrence of obesity and metabolic syndrome in middleaged men depends on both the training intensity and the level of physical efficiency. Training with an energy expenditure above $2000 \mathrm{kcal} /$ week accompanied by a high level of oxygen expenditure constitutes a significant protective factor against developing obesity and metabolic syndrome. Men of the highest level of physical activity have a 2-3-fold lower risk of obesity and metabolic syndrome development at middle age and many anthropometric and efficiency indices have been shown to make them look 10 or 20 years younger [26].

\section{Body Mass Index}

No statistically significant differences regarding BMI were observed over the time ranges in the study group of men living in Łódź. This result, as well as the one associated with physical activity, should be considered with due caution. A negative effect of overweight and obesity on longevity seems to be a commonly-known problem, not only among epidemiologists and physicians but also among "normal citizens". Nevertheless, the fact that at least half the populations of developed countries are characterised by overweight or obesity, and 2/3 of the adult population in the USA are afflicted with these ailments, what more, nearly half of the population are obese [27], empahsised the need for further analysis. Numerous reports on the relationship between premature mortality and body mass reveal the presence of a J- or U-shaped association [28,29], although some studies suggect that obesity 
can be beneficial for our general health [30], that it can exert only a slight effect on mortality rate [31] or there is no association between body mass measured with the BMI index and mortality [32]. A study by Berrington de Gonzaleza et al. performed on a very large sample of 1.5 million adults shows that the lowest risk of death has been observed among the people with BMI scores between 22.5 and 24.99 [27], which reminds us that also being underweight exerts a negative impact on health. Similar results were obtained from an analysis carried out by the Prospective Studies Collaboration including a sample of 0.9 million subjects [33].

\section{Multiple risk factors}

The study results related to three factors, tobacco smoking, alcohol and diet, are in accordance with a combined analysis performed in the years 2001-2005 by Manuel et al. on the effect on longevity of five health-related behaviours, including tobacco smoking, alcohol drinking, physical activity, diet and stress. The sample used in the analysis included 68,200 respondents and the results were compared with death statistics in the examined territory from 2001-2010. Complying with the recommendations concerning those health-related behaviours among Ontario residents should result in the prolongation of life duration by 7.5 years, compared to the average value. On the other hand, the presence of risky health behaviours, i.e. tobacco smoking, alcohol abuse, lack of physical activity, inadequate diet and the stress accompanying all these behaviours, lead to a decrease in longevity by 2.5 years. Thus, the difference in life duration among representatives of two extreme attitudes to health-related behaviours among Ontario residents is 20 years, which represents $25 \%$ of mean longevity in this province. Generalizing the analysed values, it may be stated that healthy behaviours increase life duration by $9 \%$, while their neglecting shortens life by $15 \%$ [34]. In conclusion, the authors mention the well-known statement, which should be continuously emphasised, that healthy behaviours not only add "years to life" but also add "life to years", which means an increase in average "healthy" lifespan and improvement in quality of life [35].

Finally, the present study has not confirmed the presence of any beneficial effect of physical activity on prolongation of human longevity. This situation might result from the low level and irregular nature of the physical activity of the men studied, which in a relatively short period of observation did not have any effect on health. The authors have obtained results from long-term studies, representing 20-30 years of continuous observations, of a cohort regularly taking part in sports, and plan to present them in the nearest future.

\section{CONCLUSIONS}

On the basis of the analysed longevity of men with identified risk factors of cardiovascular diseases it has been found that:

1. A diet rich in fish and high consumption of yellow cheese are positive predictors, while additional use of table salt at meals and consumption of cakes are negative predictors of longevity.

2. In our study, alcohol consumed in moderate amounts seemed to favourably influence longevity of men; however, it must be remembered that even moderate use of alcohol may lead to many adverse health effects.

3. Tobacco smoking is a definitely adverse factor influencing the longevity of male subjects.

4. Although it is clear that the presented results need to be confirmed in a larger population of male citizens of Łódź, taking into account the poor mortality statistics in this region, a more effective healthimprovement policy has to be implemented without further delay. 


\section{REFERENCES}

1. World Health Organization. Global status report on noncommunicable diseases 2010 [cited 2013 Jun 5]. Geneva: WHO; 2011. Available from http://www.who.int/nmh/publications/ncd_report_full_en.pdf.

2. Alwan A, MacLean DR, Riley LM, d'Espaignet ET, Mather CD, Stevens GA, et al. Monitoring and surveillance of chronic non-communicable diseases: Progress and capacity in high-burden countries. Lancet 2010;376:1861-8. DOI: 10.1016/ S0140-6736(10)61853-3.

3. World Health Organization. A comprehensive global monitoring framework for NCDs and voluntary global targets for the prevention and control of NCDs [cited. 2013 Jun 5]. Geneva: WHO; 2011. Available from http:/www.who.int/nmh/events/2011/consultation_dec_2011/WHO_Discussion_Paper_FINAL.pdf.

4. Partner in Business Strategies. Healthy lifestyle [cited 2013 Jun 5]. Available from http://www.pbsdga.pl/x.php/1,812/ Zdrowy-styl-zycia.html [in Polish].

5. Erikson MK, Hagberg L, Lindholm L, Malmgren-Olsson E-B, Oesterlind J, Eliasson M. Quality of life and cost-effectiveness of a 3-year trial of lifestyle intervention in primary health care. Arch Intern Med 2010;170:1470-9. DOI: 10.1001/archinternmed.2010.301.

6. Lianov L, Johnson M. Physician competencies for prescribing lifestyle medicine. JAMA 2010;304:202-3. DOI: 10.1001/ jama.2010.903.

7. Wojtyniak B, Rabczenko D, Pokarowski P, Poznańska A, Stokwiszewski J. Polish population mortality in 2008-2010. Warszawa: Narodowy Instytut Zdrowia Publicznego - Państwowy Zakład Higieny; 2012 [in Polish].

8. Drygas W, Bielecki W, editors. State of health, attitudes and health behaviours of the residents of Lodz. Report of the research carried out under CINDI-WHO programme. Łódź: Medical University in Lodz; 2002 [in Polish].

9. World Health Organization. Social inequalities in health in Poland. Publication 2012 [cited 2013 Jun 5]. Available from http://www.euro.who.int/en/what-we-publish/abstracts/ social-inequalities-in-health-in-poland.
10. Kromann N, Green A. Epidemiological studies in the upernavik district, Greenland: Incidence of some chronic diseases 1950-1974. Acta Med Scand 1980;208:401-6. DOI: 10.1111/j.0954-6820.1980.tb01221.x.

11. Whelton SP, He J, Munter P. Meta-analysis of observational studies on fish intake and coronary heart disease [cited 2013 Jun 5]. Am J Cardiol 2004;93:1119-23. DOI: 10.1016/j.amjcard.2004.01.038. Available from http://www.sciencedirect. com/science/article/pii/S0002914904001286.

12. Myint PK, Welch AA, Bingham SA, Luben RN, Wareham NJ, Day NE, et al. Habitual fish consumption and risk of incident stroke: The European prospective investigation into Cancer (EPIC)-Norfolk prospective population study [cited 2013 Jun 5]. Public Health Nutr 2006;9:882-8. DOI: 10.1017/PHN2006942. Available from http://journals. cambridge.org/download.php?file $=\% 2 \mathrm{FPHN} \% 2 \mathrm{FPHN} 90$ 7\%2FS1368980006001467a.pdf $\&$ code $=1 \mathrm{de} 5954 \mathrm{cac} 1104885$ 89a28152cc6112a.

13. Patel PS, Sharp SJ, Luben RN, Khaw K-T, Bingham SA, Wareham NJ, et al. Association between type of dietary fish and seafood intake and the risk of incident type 2. Diatabes Care 2009;4:174-82. DOI: 10.2337/dc09-0116 [in Polish].

14. Suliga E. Health behaviours connected with the old and adult feeding [cited 2013 Jun 5]. Hyg Pub Health 2010;45(1):44 8. Available from http://www.dc.viamedica.pl/abstrakt. phtml?id=22\&indeks_art=142 [in Polish].

15. World Health Organization. Diet, Nutrition and the prevention of chronic diseases: Report of a joint WHO/FAO expert consultation. WHO Technical Report. Series 916. Geneva: WHO; 2003.

16. Hu FB. Diet and lifestyle influences on risk of coronary heart disease [cited 2013 Jun 5]. Curr Atheroscler Rep 2009;11:25763. DOI: 10.1007/s11883-009-0040-8. Available from http:// missclasses.com/mp3s/Prize\%20CD\%202010/CVD/review. pdf.

17. Kłosiewicz-Latoszek L. Food recommendations and prevention of chronic diseases. Probl Hig Epidemiol 2009;90(4):44750 [in Polish]. 
18. Manttari M, Tenkanen T, Alikoski T. Alcohol and coronary heart disease: The role of HDL-cholesterol and smoking [cited 2013 Jun 5]. J Intern Med 1997;241(2):157-63. DOI: $\quad 10.1046 / j .1365-2796.1997 .98108000 . x . \quad$ Available from http://onlinelibrary.wiley.com/doi/10.1046/j.13652796.1997.98108000.x/pdf.

19. Jelski W, Sani TA, Szmitkowski M. The alcohol influence on circulatory system. Pol Merkuriusz Lek 2006;21:299-305 [in Polish].

20. Bielecki W. Functional disease syndrome. Sociological myth or reality? Łódź: Wydawnictwo Uniwersytetu Łódzkiego; 2007 [in Polish].

21. Christensen K, Vaupel JW. Determinants of longevity: Genetic, environmental and medical factors [cited 2013 Jun 5]. J Intern Med 1996;240(6):333-41. DOI: 10.1046/j.13652796.1996.d01-2853.x. Available from http://onlinelibrary. wiley.com/doi/10.1046/j.1365-2796.1996.d01-2853.x/pdf.

22. Kwaśniewska M, Kostka T, Drygas W. Red wine in medicine: Panacea, fashion or... riskfactor? Przegl Lek 2000;57(5):300-4 [in Polish].

23. Kowalska A, Drygas W. Changes in the frequency of smoking of the 'quit \& win' contest participants during the year following the end of the 2nd International Antinicotine Campaign in Poland. In: Drygas W, editor. Progress in the Prevention and Treatment of Chronic Non-Communicable Diseases. Lódź: Medical University of Lodz; 2000 [in Polish].

24. Tyczyński JE. Lung cancer mortality and tobacco smoking in Poland - Will we observe further changes in mortality in Ligot of recent smoking patterns? [cited 2013 Jun 5]. Now J Oncol 2004;54(4):333-41. Available from http://www.nowotwory.edu.pl/pobierz.php?id=734.

25. Paffenbarger RS, Hyde RT, Hsieh CC, Wing AL. Physical activity, other life-style patterns, cardiovascular disease and longevity. Acta Med Scand Suppl 1986;711:85-91. DOI: 10.1111/ j.0954-6820.1986.tb08936.x.

26. Drygas W, Jegier A, Bednarek-Gejo A, Kwaśniewska M, Dziankowska-Zaborszczyk E, Kostka T. Standard of the physical activity as a factor determinnig the occurrence of obesity and metabolic syndrome among the middle-age male. Result of long-term prospective research. Przegl Lek 2005;62(3):8-13 [in Polish].

27. Berrington de Gonzalez A, Hartge P, Cerhan JR, Flint AJ, Lindsay H, MacInnis RJ, et al. Body-mass index and mortality among 1.46 million white adults [cited 2013 Jun 5]. N Engl J Med 2010;363(23):2211-9. DOI: 10.1056/NEJMoa1000367. Available from http://www.ncbi.nlm.nih.gov/ pmc/articles/PMC3066051.

28. Kaleta D, Kwaśniewska M, Bednarek-Gejo A, Dziankowska-Zabojszczyk E, Jegier A, Kostka T, et al. Estimation of the health consequences regarding body mass changes among middle-age male - Prospective research [cited 2013 Jun 5]. Przegl Lek 2005;62(3):18-22 [in Polish].

29. Schooling CM, Lam TH, Li ZB, Ho SY, Can WM, Ho KS, et al. Obesity, physical activity, and mortality in a prospective Chinese elderly cohort [cited 2013 Jun 5]. Arch Intern Med 2006;166:1498-504. DOI: 10.1001/archinte.166.14.1498. Available from http://archinte.jamanetwork.com/article. aspx?articleid $=410695$.

30. Orpana HM, Bertholt JM, Kaplan MS, Feeny DH, McFarland B, Ross NA. BMI and mortality: Results from a national longitudinal study of Canadian adults [cited 2013 Jun 5]. Obesity 2010;18:214-8. DOI: 10.1038/oby.2009.191. Available from http://xa.yimg.com/kq/groups/9196911/56873634/ name/oby2009191a.pdf.

31. Pischon T, Boeing H, Hoffman K, Bergmann M, Schulze MB, Overvad K, et al. General and abdominal adiposity and risk of death in Europe [cited 2013 Jun 5]. N Engl J Med 2008;359(20):2105-20. DOI: 10.1056/NEJMoa0801891. Available from http://www.nejm.org/doi/ pdf/10.1056/NEJMoa0801891.

32. Sui X, LaMonte MJ, Laditka JN, Hardin JW, Chase N, Hooker SP, et al. Cardiorespiratory fitness and adiposity as mortality predictors in older adults [cited 2013 Jun 5]. JAMA 2007;298:2507-16. DOI: 10.1001/jama.298.21.2507. Available from http:/jama.jamanetwork.com/article. aspx?articleid=209641. 
33. PS Collaboration. Body-mass index and cause-specific mortality in 900000 adults: Collaborative analyses of 57 prospective studies [cited 2013 Jun 5]. Lancet 2009;373(9669):1083-96. DOI: 10.1016/S0140-6736(09)60318-4. Available from http:// www.ncbi.nlm.nih.gov/pmc/articles/PMC2662372.

34. Manuel DG, Perez R, Bennett C, Rosella L, Taljaard M, Roberts M, et al. Seven more years: The impact of smoking, alcohol, diet, physical activity and stress on health and life expectancy in Ontario. An ICES/PHO Report [cited 2013 Jun
5]. Toronto: Institute for Clinical Evaluative Sciences and Public Health; 2012. Available from http://www.ices.on.ca/ file/HealthImpact_ICES_Report3_web_jp21.pdf.

35. Manuel DG, Schultz SE. Adding life to years and years to life: Life and health expectancy in Ontario [cited 2013 Jun 5]. Toronto: Institute for Clinical Evaluative Sciences; 2001. Available from http://www.ices.on.ca/file/Atlas $\% 20-\% 20$ Adding $\% 20$ years $\% 20$ to $\% 20$ life $\% 20$ and $\% 20$ life $\% 20$ to $\% 20$ years.pdf.

This work is available in Open Access model and licensed under a Creative Commons Attribution-NonCommercial 3.0 Poland License - http://creativecommons.org/ licenses/by-nc/3.0/pl/deed.en. 